\title{
OPTIMALISASI TUMBUH KEMBANG BAYI DAN BALITA MELALUI PEMBERDAYAAN KELUARGA DALAM PEMANFAATAN BUKU KIA DI SURABAYA \\ OPTIMIZING THE GROWTH OF BABIES AND CHILDREN THROUGH EMPOWERMENT OF THE FAMILY IN THE UTILIZATION OF KIA BOOKS IN SURABAYA
}

\author{
Oleh: \\ Sri Utami ${ }^{1}$, Rekawati Susilaningrum ${ }^{2}$, Dwi Purwanti ${ }^{3}$ \\ ${ }^{1}$ Poltekkes Kemenkes Surabaya \\ ${ }^{1}$ sri.utami@poltekkesdepkes-sby.ac.id
}

\begin{abstract}
Abstrak
Optimalisasi pertumbuhan dan perkembangan pada masa balita merupakan hal penting yang perlu dilakukan dalam upaya mencetak generasi penerus yang berkualitas. Keluarga mempunyai peran penting dalam menyiapkan anak mencapai tumbuh kembang optimal, melalui stimulasi dan pemantauan tumbuh kembang dengan menggunakan buku KIA. Di Jawa Timur, kepemilikan buku KIA sudah di atas $80 \%$ namun Kepemilikan buku KIA belum diimbangi dengan pemahaman isinya serta pemanfaatannya oleh ibu. Kegiatan pengabdian kepada masyarakat ini bertujuan untuk meningkatkan pemahaman keluarga tentang buku KIA sebagai upaya optimalisasi tumbuh kembang balita. Metode kegiatan pengabdian masyarakat ini adalah dengan wawancara konseling, dan pemeriksaan fisik dengan sasaran keluarga (ibu) yang mempunyai anak bayi dan balita. Jumlah sasaran 30 keluarga. Hasil kegiatan yaitu pertumbuhan balita sebagian besar (83\%) status gizi (BB/T) normal, Sebagian besar $(77 \%)$ status gizi berdasarkan TB/Umur kategori normal. Hampir seluruhnya (97\%) perkembangan sesuai usia. Setelah dilakukan konseling terdapat peningkatan pengetahuan ibu tentang pemanfaatan buku KIA dalam upaya optimalisasi tumbuh kembang dari $87 \%$ menjadi $100 \%$ berpengetahuan baik, dari $97 \%$ sikap positif menjadi seluruhnya $100 \%$ sikap positif, dan dari $83 \%$ Tindakan sesuai dalam pemanfaatan buku KIA, menjadi $97 \%$ sesuai. Konseling dapat meningkatkan pengetahuan, sikap dan tindakan ibu sebesar $15 \%$ dalam pemanfaatan buku KIA.
\end{abstract}

Kata Kunci: Pemberdayaan, Buku KIA, Tumbuh Kembang Bayi dan Balita.

\begin{abstract}
Optimizing child growth and development is one of the priority efforts in preparing quality generations of Indonesian children. Families have an important role in preparing children to achieve optimal growth and development, through stimulation and monitoring of growth and development using the $\mathrm{MCH}$ Handbook. In East Java, ownership of KIA books is above $80 \%$ (Ministry of Health RI, 2018), but ownership of $\mathrm{MCH}$ books has not been matched by understanding the contents and their use by mothers. The purpose of this community service is to increase family understanding of the $\mathrm{MCH}$ book as an effort to optimize the growth and development of toddlers. The method used is interview counseling, targeting families (mothers) who have babies and toddlers. The target number is 30 families. Result are most of the children under five (83\%) had normal nutritional status (BW / T). Most (77\%) nutritional status based on TB / age was normal. Almost all (97\%) developed according to age. After counseling was carried out, there was an increase in the mother's knowledge about the use of $\mathrm{MCH}$ books in an effort to optimize growth and development from $87 \%$ to $100 \%$ good knowledge, from $97 \%$ positive attitudes to $100 \%$ positive attitudes, and from $83 \%$ appropriate actions in the use of the KIA book, to $97 \%$ corresponding. The counseling provided can increase the knowledge, attitudes and actions of mothers about $15 \%$ in the use of the $\mathrm{MCH}$ book.
\end{abstract}

Keywords: Empowerment, MCH Handbook, Infant and Toddler Growth.

\section{PENDAHULUAN}

Dalam rangka mewujudkan derajat kesehatan masyarakat yang optimal, pemerintah meluncurkan Program Indonesia Sehat dengan Pendekatan Keluarga yang terdiri atas 4 (empat) prioritas. Empat prioritas yang dimaksud adalah penurunan angka kematian ibu dan bayi, penurunan prevalensi balita pendek (stunting), penanggulangan penyakit menular, dan penanggulangan penyakit tidak menular. Dalam rangka "menurunkan Angka Kematian Ibu (AKI) dan Angka Kematian Bayi (AKB)" yang merupakan prioritas yang pertama, kegiatan intervensi dilakukan dengan mengikuti siklus hidup manusia yaitu pelayanan saat ibu hamil dan bersalin, pelayanan pada bayi dan ibu menyusui, pelayanan pada balita, pelayanan pada anak usia sekolah, pelayanan 
pada remaja dan dewasa muda (Kemenkes RI, 2016b).

Pelayanan bayi dan balita perlu mendapatkan perhatian dari semua pihak, karena pada periode ini terjadi pertumbuhan dan perkembangan secara cepat yang merupakan dasar untuk kehidupan selanjutnya. Dalam Peratutan Menteri Kesehatan RI tahun 2014 no 25 dijelaskan bahwa "Upaya Kesehatan Anak dilakukan sejak janin dalam kandungan sampai berusia 18 (delapan belas) tahun melalui pelayanan 1) kesehatan janin dalam kandungan, 2) kesehatan Bayi Baru Lahir, 3) kesehatan Bayi, Anak Balita, dan Prasekolah, 4) kesehatan Anak Usia Sekolah dan Remaja, 5) perlindungan kesehatan anak" (Menkes, 2014).

Upaya kesehatan pada bayi, anak balita dan Pra sekolah perlu dilakukan secara dini dan berkesinambungan terutama dalam pemantauan tumbuh kembangnya, sehingga jika ada masalah bisa segera dilakukan tindakan. Parameter yang digunakan untuk pemantauan pertumbuhan, tentunya berbeda dengan paramenetr untuk pemantauan perkembangan meskipun keduanya mempunyai keterkaitan. Pemantauan pertumbuhan sebaiknya sudah harus dilakukan sejak anak lahir sampai usia 72 bulan yaitu dengan penimbangan berat badan tiap bulan, pengukuran tinggi badan tiap 3 (tiga) bulan dan pengukuran lingkar kepala sesuai jadwal. Sedangkan pemantauan perkembangan dapat dilakukan dengan memberikan stimulasi, melakukan deteksi dini dan intervensi tumbuh kembang tiap 3 (tiga) bulan pada anak usia 0 sampai 1 tahun tiap 6 (enam) bulan pada anak usia 1 sampai 6 tahun.

Pemantauan tumbuh kembang bisa dilakukan oleh orang tua atau keluarga balita dengan menggunakan Buku KIA. "Buku KIA ini telah digunakan di Indonesia sejak tahun 2004 dan ditetapkan dengan keputusan Menteri Kesehatan Republik Indonesia nomor 284/Menkes/SK/III/2004 tentang Buku Kesehatan Ibu dan Anak". Buku KIA "merupakan alat untuk mendeteksi secara dini adanya gangguan atau masalah kesehatan ibu dan anak, alat komunikasi dan penyuluhan dengan informasi yang penting bagi ibu, keluarga dan masyarakat mengenai pelayanan, kesehatan ibu dan anak termasuk rujukannya dan paket (standar) pelayanan $\mathrm{KIA}$, gizi, imunisasi, dan tumbuh kembang balita". Ibu dan anak perlu memiliki catatan yang lengkap sejak ibu hamil sampai dengan selesai masa nifas dan anaknya sejak lahir hingga berusia 5 (lima) tahun.

Salah satu kegiatan nyata untuk membantu meningkatkan derajat kesehatan balita adalah dengan kampanye dan pemberdayaan masyarakat yaitu penerapan buku KIA.
Pemakaian buku KIA tidak secara langsung menurunkan angka kematian ibu, Bayi dan Balita. Namun dengan pemanfaatan buku KIA, ibu dan keluarga dapat meningkatkan upaya preventif, promotif pada masalah kesehatan ibu dan anak terhadap penyakit atau gangguan yang dapat sebagai penyebab penyakit yang berkontribusi terhadap kematian ibu dan anak (Kemenkes RI, 2016a). Berdasarkan data Riskesdas 2018, proporsi kepemilikan buku KIA pada anak 0-59 bulan sekitar 65,9\%. Angka ini mengalami kenaikan jika dibandingkan Riskesdas tahun 2013 sebesar 52,6\%. Di Jawa Timur, kepemilikan buku KIA sudah diatas $80 \%$ (Kemenkes RI, 2018).

Berkaitan dengan upaya pelayanan Kesehatan anak, didalam buku KIA, juga tergambar keadaan pertumbuhan dan perkembangan anak dan upaya stimulasinya. Upaya deteksi tumbuh kembang, umumnya masih terbatas pada pemantauan pertumbuhan berat badan yang digunakan untuk menentukan status gizi. Di Surabaya anak baduta yang mengalami BGM sekitar 0,7. Prosentase tersebut sama dengan rata-rata BGM di Jawa Timur. Sedangkan prosentase anak balita yang BGM sekitar 0,6\%. Prosentase ini lebih tinggi dibanding rata-rata di jawa Timur yang sebesar 0,5. Sedangkan yang mengalami gizi buruk ada sekitar 278 dari jumlah balita sebanyak 127.211 orang (Dinas Kesehatan Prop Jawa Timur, 2017).

Status gizi anak tersebut setidaknya mencerminkan keadaan pertumbuhan anak. Untuk itu penimbangan berat badan secara rutin bisa mengetahui apakah anak tergolong normal atau ada masalah. Jumlah bayi yang ditimbang merupakan salah satu indikator capaian target yang ditetapkan pemerintah. Ada beberapa puskesmas di Surabaya, belum memenuhi target jumlah balita yang ditimbang, salah satunya adalah puskesmas Pacar keling. Di Puskesmas Pacar Keling, tidak ada anak balita yang mengalami gizi buruk atau BGM, namun jumlah balita yang ditimbang $74,2 \%$, sedangkan anak dibawah 2 tahun (baduta) sekitar 66,76\%. Prosentase ini masih dibawah rata-rata seluruh puskesmas di Surabaya yang mencapai sekitar 85\% (Dinkes, 2018).

Balita yang ditimbang rutin, dapat memberikan gambaran keadaan pertumbuhan anak yang penting diketahui oleh orang tua. Jika ada gangguan, setidaknya orang tua dapat menentukan tindakan selanjutnya. Seharusnya tidak hanya aspek pertumbuhan saja yang dipantau, aspek perkembangan tidak kalah pentingnya. Pertumbuhan dan perkembangan anak merupakan dua hal yang berbeda dalam pengukurannya namun saling mempengaruhi. Aspek perkembangan ini yang masih banyak diabaikan oleh orang tua. 
Adanya masalah pertumbuhan dan perkembangan diminimalkan jika orang tua bisa memahami dan dapat melakukan pemantauan tumbuh kembang sebagaimana yang dijelaskan pada buku KIA. Banyak ibu yang sudah memiliki buku KIA, namun belum diimbangi dengan pemahaman isinya. Jika orang tua memahami tentang keadaan tumbuh kembang anaknya sebagaimana yang terdapat dalam buku KIA, tentunya orang tua bisa melakukan upaya-upaya agar anaknya tumbuh dan berkembang secara normal. Dengan demikian dapat diminimalkan masalah-masalah yang berkaitan dengan tumbuh kembang.

Buku KIA yang terisi lengkap juga sebagai bentuk tanggungjawab orang tua terhadap kesehatan anaknya. Seringkali ibu membawa buku KIA saat memeriksakan anaknya ke puskesmas, namun tidak memahami isi bukunya. Buku KIA jarang dibaca, dipelajari oleh ibu dan keluarga dengan berbagai alasan antara lain tidak sempat, tidak mengerti, dan menganggap buku KIA adalah buku catatan untuk tenaga kesehatan, bahkan ditemukan buka KIA sering sudah dalam keadaan rusak. Menurut Kirana, Dirjen Kesmas Kemenkes RI, saat ini, komitmen dalam pemanfaatannya di masyarakat masih belum sesuai harapan. Sehingga perlu penguatan terutama kelengkapan pengisiannya oleh petugas kesehatan, kader dan orangtua. Selain itu juga dibutuhkan kesadaran para ibu (orang tua) untuk menyimpan dan selalu membawa buku KIA saat melakukan pemeriksaan di fasilitas pelayanan kesehatan. (Kirana, 2018)

Jika Buku KIA diterapkan secara benar akan berdampak pada peningkatan pengetahuan ibu dan keluarga tentang upaya memelihara kesehatan ibu dan anak, dapat menggerakan dan memberdayakan masyarakat untuk hidup sehat, meningkatkan akses masyarakat terhadap pelayanan kesehatan yang berkualitas serta meningkatkan sistem survailance, monitoring dan informasi kesehatan.

Sebagai upaya mengoptimalkan pemanfaatan buku KIA dalam upaya deteksi tumbuh kembang, perlu adanya suatu kegiatan untuk meningkatkan perilaku ibu untuk lebih memahami pentingnya buku KIA. Poltekkes Kemenkes Surabaya selaku institusi pendidikan kesehatan bisa berperan aktif untuk mendukung program Kementerian Kesehatan dalam pemberdayaan masyarakat melalui Tri Darma Perguruan Tinggi. Berkaitan dengan permasalahan belum efektifnya pemanfaatan buku KIA untuk pemantauan pertumbuhan anak, maka perlu ada suatu pelatihan pada orang tua atau keluarga sebagai bentuk pengabdian kepada masyarakat yang dilaksanakan oleh dosen dan mahasiswa Poltekkes Kemenkes Surabaya, khususnya dari Prodi kebidanan Sutomo. Pelatihan ini diharpkan dapat meningkatkan akses pelayanan kesehatan yang bermutu bagi setiap orang pada setiap tahapan kehidupan dengan pendekatan satu kesatuan pelayanan (continuum of care) melalui intervensi komprehensif (promotif, preventif, kuratif dan rehabilitatif) secara paripurna

\section{METODE}

Metode yang digunakan adalah:

1. Penilaian dan pengukuran berat badan, tinggi badan, usia anak

2. Wawancara / interview untuk upaya stimulasi

3. Konseling pada ibu tentang stimulasi dan pemamtauan tumbuh kembang balita dengan menggunakan buku KIA.

\section{HASIL DAN PEMBAHASAN}

Hasil disajikan dalam bentuk tabel distribusi frekuesi tentang karakteristik ibu dan balita, status pertumbuhan dan perkembangan balita, serta kemampuan ibu yang meliputi pengetahuan, sikap dan Tindakan ibu dalam upaya optimalisasi pertumbuhan dan perkembangan KIA melalui pemanfaatan buku KIA. Hampir setengahnya (43\%) ibu berusia 31 35 tahun, hampir seluruhnya (83\%) sebagai ibu rumah tangga, Sebagian besar $(57 \%)$ balita berjenis kelamin perempuan, hampir separuhnya $(30 \%)$ balita berusia 4-5 tahun, Sebagian besar $(83 \%)$ stutus gizi $(\mathrm{BB} / \mathrm{T})$ dalam kategori normal, Sebagian kecil (13\%) dalam kategori kurus. Sebagian besar $(77 \%)$ status gizi berdasarkan TB/Umur dalam kategori normal, Sebagian kecil (13\%) dalam kategori pendek. Hampir seluruhnya (97\%) perkembangan sesuai usia dan Sebagian kecil (3\%) dalam kategori kemungkinan mengalami penyimpangan. Setelah dilakukan konseling terdapat peningkatan pengetahuan ibu tentang pemanfaatan buku KIA dalam upaya optimalisasi tumbuh kembang balita dari $87 \%$ menjadi $100 \%$ berpengetahuan baik, dari $97 \%$ sikap positif dan $3 \%$ sikap negative menjadi seluruhnya $100 \%$ sikap positif, dan dari $83 \%$ Tindakan sesuai dan $17 \%$ Tindakan dalam pemanfaatan buku KIA, menjadi $97 \%$ sesuai dan hanya $3 \%$ dalam kategori tidak sesuai. Hasil pre test dan post test ada kenaikan pengetahuan, sikap yang postif dan Tindakan yang sesuai terhadap pemanfaatan buku KIA

Hasil tersebut secara rinci dapat disajikan dalam tabel berikut. 
Tabel 1. Distribusi frekuensi karakteristik ibu dan bayi, balita

\begin{tabular}{|c|c|c|}
\hline Indikator & Frekuensi & Prosentasi (\%) \\
\hline \multicolumn{3}{|l|}{ Rentang Usia Ibu } \\
\hline $21-25$ tahun & 3 & 10 \\
\hline $26-30$ tahun & 5 & 17 \\
\hline $31-35$ tahun & 13 & 43 \\
\hline $36-40$ tahun & 9 & 30 \\
\hline \multicolumn{3}{|l|}{ Pekerjaan ibu } \\
\hline lbu rumah tangga & 25 & 83 \\
\hline Bekerja diluar & 5 & 17 \\
\hline \multicolumn{3}{|l|}{ Jenis Kelamin Balita } \\
\hline Perempuan & 17 & 57 \\
\hline Laki-laki & 13 & 43 \\
\hline \multicolumn{3}{|l|}{ Usia Balita } \\
\hline Kurang dari 6 bulan & 1 & 3 \\
\hline 6 bulan - 1 tahun & 3 & 10 \\
\hline 1 - 2 tahun & 3 & 10 \\
\hline $2-3$ tahun & 7 & 23 \\
\hline 3 - 4 tahun & 7 & 23 \\
\hline $4-5$ tahun & 9 & 30 \\
\hline \multicolumn{3}{|l|}{ Status Gizi (BB/TB) } \\
\hline Normal & 25 & 83 \\
\hline Kurus & 4 & 13 \\
\hline Kurus sekali & 0 & 0 \\
\hline Gemuk & 1 & 3 \\
\hline \multicolumn{3}{|l|}{ Status Gizi (TB/U) } \\
\hline Normal & 23 & 77 \\
\hline Pendek & 4 & 13 \\
\hline Sesuai & 29 & 97 \\
\hline Meragukan & 0 & 0 \\
\hline Penyimpangan & 1 & 3 \\
\hline
\end{tabular}

Tabel 2. Distribusi Kemampuan (pengetahuan, sikap dan Tindakan) Ibu dalam Pemanfaatan Buku KIA

\begin{tabular}{|c|c|c|c|c|}
\hline \multirow{2}{*}{ Indikator } & \multicolumn{2}{|c|}{ Pre } & \multicolumn{2}{c|}{ Post } \\
\cline { 2 - 5 } & frekuensi & Persentase (\%) & frekuensi & Persentase (\%) \\
\hline Pengetahuan & & & & \\
\hline 1. Baik & 26 & 87 & 30 & 100 \\
\hline 2. Cukup & 4 & 13 & - & - \\
\hline 3. Kurang & - & - & - & - \\
\hline Sikap & & & 30 & 100 \\
\hline 1. Positif & 29 & 97 & - & - \\
\hline 2. Negatif & 1 & 3 & & 97 \\
\hline Tindakan & & & 29 & 3 \\
\hline 2. Sesuai & 25 & 83 & 1 & \\
\hline
\end{tabular}

Kegiatan pemberdayaan masyarakat dalam optimalisasi tumbuh kembang balita dilaksanakan melalui beberapa kegiatan yaitu pre test, wawancara, observasi, konseling, dan diakhiri dengan post test 

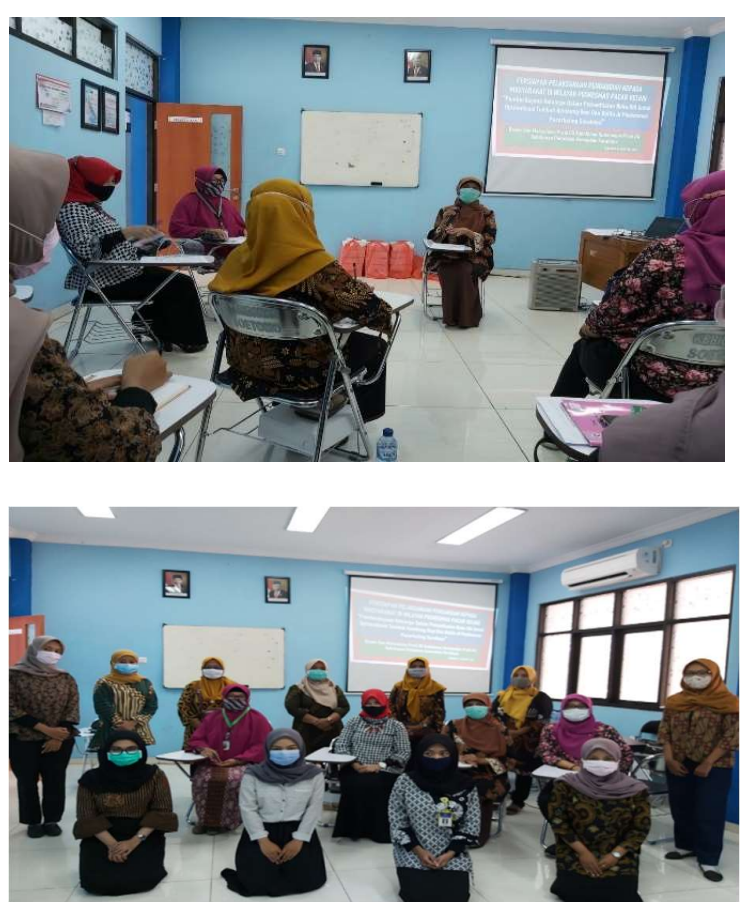

Foto Kegiatan koordinasi dengan tenaga bidan Puskesmas dan para kader, serta tim pengabmas dalam rangka persiapan kegiatan.

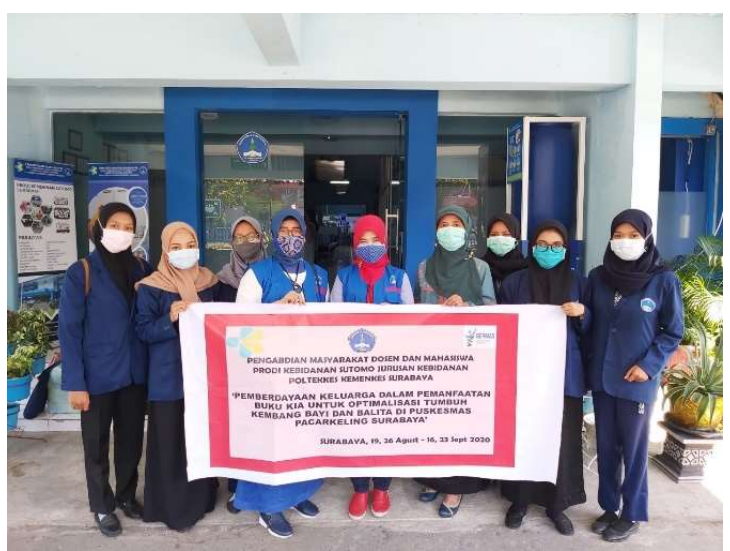

\section{Kegiatan wawancara dan observasi}

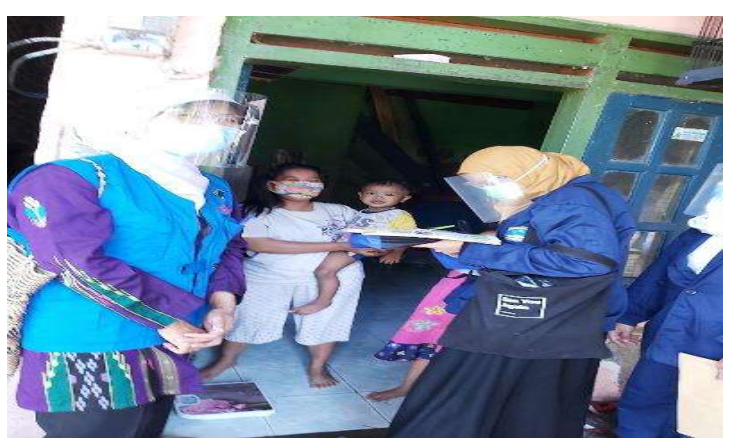

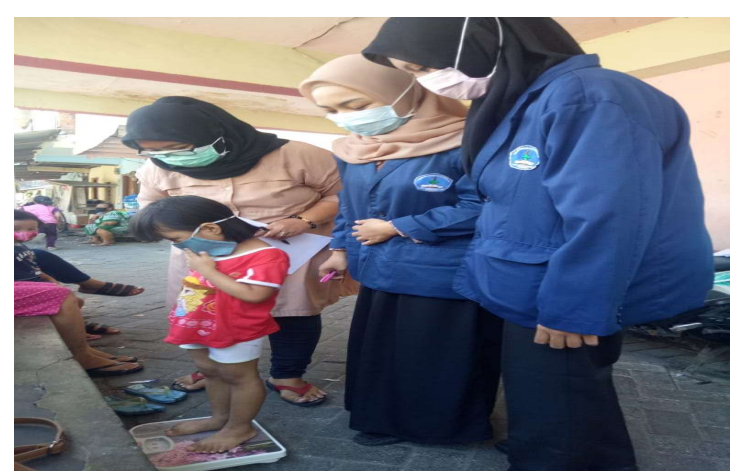

Kegiatan konseling pada keluarga / ibu balita tentang pemanfaatan buku KIA dalam optimalisasi tumbuh kembang anak.
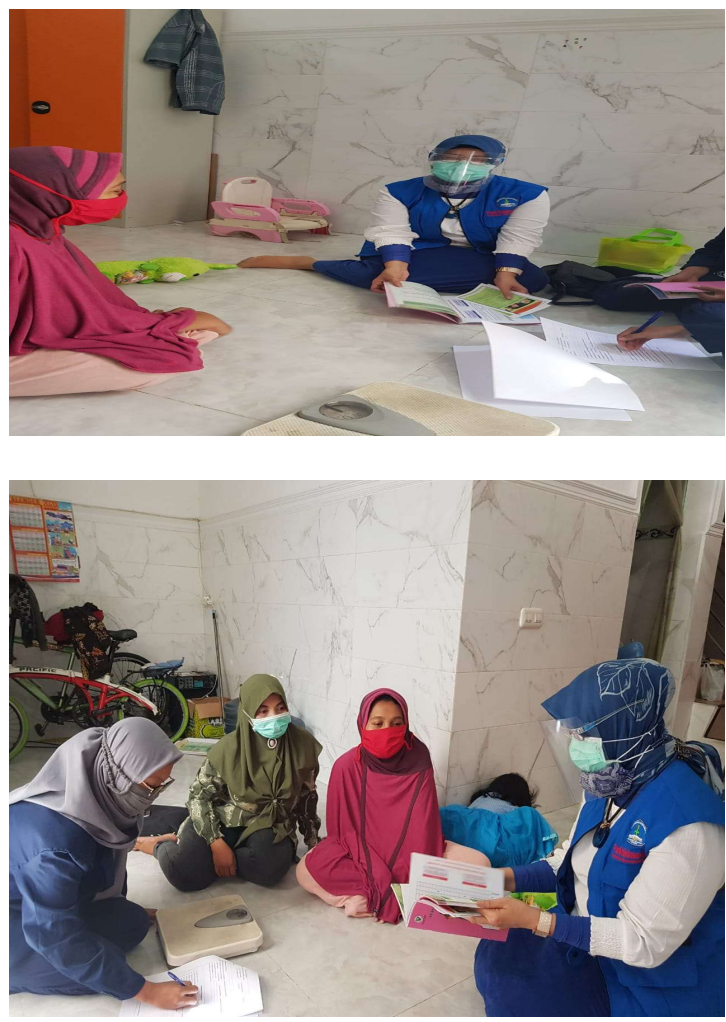

\section{Kegiatan Pemeriksaan Fisik dan konseling}

\section{Upaya Pemberdayaan Keluarga}

Pemberdayaan keluarga merupakan mekanisme yang memungkinkan terjadinya perubahan kemampuan keluarga sebagai dampak positif dari intervensi yang berpusat pada keluarga dan tindakan promosi Kesehatan. "Konsep pemberdayaan keluarga memilki tiga komponen utama, yaitu: pertama, bahwa semua keluarga telah memiliki kekuatan dan mampu membangun kekuatanitu. Kedua, kesulitan keluarga dalam memenuhi kebutuhan mereka bukan karena ketidak mampuan untuk melakukannya, melainkan system pendukung social keluarga 
tidak memberikan peluang keluarga untuk mencapainya. Ketiga, dalam upaya pemberdayaan keluarga, anggota keluarga berupaya menerapkan keterampilan dan kompetensi dan kompetensi dalam rangka terjadinya perubahan keluarga" (Kemenkes RI, 2016).

Dari pelaksanaan kegiatan pengabdian masyarakat yang telah dilakukan dapat dijelaskan bahwa konseling pada ibu tentang pemanfaatan buku KIA untuk optimalisasi tumbuh kembang anak perlu dilakukan secara berkelanjutan. Bagian buku KIA yang seharusnya diisi oleh orang tua, masih banyak yang masih kosong. Didalam buku KIA sudah ada beberapa petunjuk tentang cara memberikan stimulasi tumbuh kembang, informasi tentang kemampuan anak sesuai usianya, tindakan yang bisa dilakukan orang tua jika anak mengalami masalah. Jika orang tua mengikuti anjuran yang tercantum dalam buku KIA, maka anak-anak akan dapat tumbuh dan berkembang secara optimal. Disamping itu orang tua dapat mengetahui kondisi anaknya tergolong normal atau ada tidak. Sehingga jika ada masalah, orang tua bisa segera memeriksakan anaknya.

Pada kegiatan pengabdian masyarakat ini, konseling tentang optimalisasi tumbuh kembang anak dengan menggunakan buku KIA telah dilakukan. Untuk itu perlu ada monitoring dari penanggung jawab program Puskesmas. Disamping itu peran kader juga penting dalam pemanfaatn buku KIA. Seringkali buku KIA dibawa oleh kader untuk memudahkan membuat laporan ke puskesmas dan dikembalikan saat kegiatan posyandu berikutnya. Jika sudah selesai, hendaknya kader segera mengembalikan bukunya pada orang tua agar bisa dipelajari.

Buku KIA perlu dioptimalkan karena "merupakan alat untuk mendeteksi secara dini adanya gangguan atau masalah kesehatan ibu dan anak, alat komunikasi dan penyuluhan dengan informasi yang penting bagi ibu, keluarga dan masyarakat" (Kemenkes RI, 2016a).

Pemberdayaan keluarga dalam bidang kesehatan khususnya pemantauan tumbuh kembang dengan menggunakan buku KIA perlu dioptimalkan agar masyarakat ikut bertanggung jawab untuk memelihara derajat kesehatan masing-masing anggota keluarga (Kemenkes RI, 2016b). Hasil penelitian yang telah dipublikasikan tentang analisis factor yang berhubungan dengan perilaku pemanfaatan buku KIA, diperoleh hasil bahwa ibu yang mendapatkan promosi kesehatan berbasis HPM (Health Promotion Model) mengalami peningkatan komitmen dalam pemanfaatan buku KIA (Rekawati S, et al, 2018).

Kegiatan pengabdian masyarakat ini mendapatkan sambutan yang positif dari masyarakat. Hal ini dapat diketahui dengan antuasiasme keluarga yang dikunjungi. Secara khusus memang tidak ada pengukuran kepuasan keluarga terhadap kegiatan ini. Namun mereka secara aktif melaporkan kondisi anaknya dan bersama-sama tim pengabdi mempelajari buku $\mathrm{KIA}$. Selama ini sebagian besar ibu mengakui jarang membaca buku KIA. Dengan kegiatan pengabdian masyarakat ini, menjadi lebih memahami buku KIA, mengetahui keadaan tumbuh kembang anaknya tergolong normal atau tidak.

\section{SIMPULAN DAN SARAN}

\section{Simpulan}

Dari kegiatan PkM yang sudah dilakukan, ada beberapa hal yang bisa disimpulkan yaitu:

1. Pemahaman ibu tentang pertumbuhan dan perkembangan anak dalam kategori baik. Namun masih ditemukan Sebagian kecil ibu dengan yang tindakannya dalam pemanfaatan buku KIA untuk pembantauan tumbuh kembang balitanya, masih kurang sesuai.

2. Hampir seluruh anak keadaan pertumbuhan dan perkembangannya dalam keadaan normal. Namun masih ditemukan Sebagian kecil dengan status gizi kurus, gemuk, dan perawakan pendek.

3. Masih ada sebagian kecil ibu yang belum memahami bahwa ada bagian dalam buku KIA yang diisi oleh orang tua. Pemahaman keluarga terutama ibu tentang peran orang tua dalam pemantauan pertumbuhan dan perkembangan anak merupakan hal yang sangat penting. Karena dengan pemahaman yang baik dari ibu, akan dapat meningkatkan motivasi ibu untuk melakukan pemantauan pertumbuhan dan perkembangan anak. Kegiatan pemantauan pertumbuhan dan perkembangan anak sebaiknya dimulai dari keluarga, dengan menggunakan instrument yang ada dalam buku KIA.

Saran

1. Perlu selalu mengingatkan ibu untuk menyempatkan membaca dan memahami isi buku KIA, menerapkan petunjuk yang ada dibuku KIA serta mengisinya jika ada bagian yang harus diisi oleh orang tua.

2. Perlu ada pemberitahuan kepada kader oleh tenaga kesehatan atau penaggungung jawab program, bahwa buku KIA yang sudah diisi, bisa segera dikembalikan ke orang tua agar bisa dipelajari oleh orang tua.

\section{DAFTAR PUSTAKA}

Dinas Kesehatan Prop Jawa Timur (2017) Profil Kesehatan Pripinsi Jawa Timur 2017. Surabaya. 
Dinkes, S. (2018) Profil Kesehatan 2018. Surabaya. Available at: http://dinkes.surabaya.go.id/portal/profilkese hatan2018.pdf.

Kemenkes RI (2016a) Buku Kesehatan Ibu dan Anak. Jakarta: Kementerian Kesehatan RI.

Kemenkes RI (2016b) Peraturan Menteri Kesehatan Republik Indonesia Nomor 39 Tahun 2016 Tentang Pedoman Penyelenggaraan Program Indonesia Sehat Dengan Pendekatan Keluarga. Jakarta.

Kemenkes RI (2018) Hasil Utama Riskesdas 2018. Jakarta.

Kirana, P. (2018) 'Buku KIA Belum Dimanfaatkan Secara Maksimal', Gatra.com.

Menkes (2014) Peraturan Menteri Kesehatan Republik Indonesia Nomor 25 Tahun 2014 Tentang Upaya Kesehatan Anak. Jakarta.

Rekawati Susilaningrum, Sri Utami, Nursalam, R. D. T. (2018) 'Analysis of factors related to behavior cognition and effects on pregnant women in maternal and child health (Mch) handbook utilisation', Indian Journal of Public Health Research \& Development (www.ijphrd.com). Indian, Vol 9 No 1, pp. 492-497. doi: 10.5958/09765506.2018.01504.8. 